\title{
5.4
}

\section{Emotion and Achievement in the Classroom}

\author{
THOMAS GOETZ \\ University of Konstanz and Thurgau University of Teacher Education \\ NATHAN C. HALL \\ McGill University
}

\section{Introduction}

With the exception of extensive research on test anxiety since the 1950s (Sarason \& Mandler, 1952; Zeidner, 2007) and on emotions in achievement settings based on attribution theory (Weiner, 1985), empirical educational research has largely neglected students' emotions. Over the past decade, however, a discernible increase in theoretical and empirical contributions on emotions in education is reflected in numerous special issues and edited volumes (Efklides \& Volet, 2005; Linnenbrink, 2006; Linnenbrink-Garcia \& Pekrun, 2011; Lipnevich \& Roberts, 2012; Schutz \& Lanehart, 2002; Schutz \& Pekrun, 2007). Nonetheless, with the exception of research on anxiety/achievement relations (e.g., Hembree, 1988; Ma, 1999; Seipp, 1991), there exist only scattered empirical findings on relations between other emotions and academic achievement (Pe krun, 2006). This lack of emphasis is reflected in a recent PsychINFO search (January 2011) for manuscript titles including "achievement" and "anxiety" (532) as compared to "enjoyment" (10), "hope" (14), "pride" (7), "anger" (8), "shame" (8), or "boredom" (3). In contrast to 1,015 titles including "achievement" and "self-concept," the relatively small number of publications in the field of emotions as compared to self-concept research is clearly evident.

\section{Research Evidence}

\section{Strength of Emotion/Achievement Relations}

Anxiety-Meta-analyses. Concerning the magnitude of emotion/achievement relations, there exist three seminal meta-analyses in which academic anxiety is exclusively evaluated. In his meta-analysis of 562 North American studies (1952-1986), Hembree (1988) explored the correlates, causes, effects, and remediation of test anxiety. The studies consisted of samples from upper elementary school to high school and included various achievement measures includ- ing test scores, course grades, and GPA. Results showed test anxiety to have typically moderate negative relations with achievement, for example, with grades in mathematics $(r=$ -.22 ), natural sciences $(r=-.21)$, and social sciences $(r=$ -.25 ). In Seipp (1991), a similar meta-analysis of $126 \mathrm{Eu}-$ ropean and North American studies (1975-1988) revealed generally moderate negative relations between anxiety and academic performance, as indicated in a population effect size of -.21 (range $=-.36$ to -.07 ). The third domain-specific meta-analysis by Ma (1999) explored anxiety and achievement relations concerning mathematics across 26 studies of elementary and secondary students, finding once again a modest population correlation of -.27 (range $=-.60$ to -.12 ). Taken together, meta-analyses findings consistently demonstrate significant, albeit moderate, negative relations typically ranging from -.20 to -.25 between anxiety and achievement outcomes.

Discrete Emotions-Single Studies. Empirical findings on relations between discrete emotions and academic achievement are clear with respect to emotion valence: Pleasant emotions (e.g., enjoyment, pride) are positively related to achievement whereas unpleasant emotions (e.g., anxiety, boredom) are negatively related (Pekrun, 2006). Further, cumulative research indicates that emotion/achievement relations are best understood as linear and not curvilinear in nature (e.g., inverted-U relationship as in Yerkes \& Dodson, 1908; see Zeidner, 1998, 2007). Concerning the strength of discrete emotions/achievement relations, recent studies indicate differences with respect to emotion type and academic domain. Goetz et al. (2012; grades $8 / 11$ ) found the mean and median within-domain relation between discrete classroom-related emotions (enjoyment, pride, anxiety, anger, boredom) and grades in multiple subject domains (mathematics, physics, German, English) to be 1.251 (range $=.04$ to $.40 ; S D=.08$ ). These values are consistent with related studies on emotion/ achievement relations in high-school and university students 
(e.g., Goetz, Cronjaeger, Frenzel, \& Lüdtke, 2010; Goetz, Frenzel, Hall, \& Pekrun, 2008; Goetz, Frenzel, Pekrun, Hall, \& Lüdtke, 2007; Pekrun, Elliot, \& Maier, 2009; Pekrun, Goetz, Daniels, Stupnisky, \& Perry, 2010). To summarize, single studies indicate mean discrete emotions/achievement relations of approximately $|.25|$.

\section{Mediating Factors in Emotion/Achievement Rela-} tions. There exist few theoretical approaches in which the mechanisms underlying discrete emotion/achievement relations are addressed. Of these models, the most prominent is a comprehensive model outlined by Pekrun, Frenzel, Goetz, and Perry (2007) that incorporates social-cognitive emotion theories as well as empirical findings concerning discrete emotions in achievement settings. In Pekrun's model, it is assumed that emotion/achievement relations are mediated by cognitive resources, motivation, strategy use, and self-regulated learning such that specific emotions impact these variables that, in turn, predict achievement outcomes. Further, the effects of emotions on mediating variables and achievement are assumed to be additionally complicated by the emotional dimensions of valence (pleasant vs. unpleasant) and activation (activating vs. deactivating). Based on these dimensions, four groups of emotions can be distinguished: positive activating emotions (e.g., enjoyment, hope, pride, gratitude); positive deactivating emotions (e.g., relaxation, contentment, relief); negative activating emotions (e.g., anger, frustration, anxiety, shame); and negative deactivating emotions (e.g., boredom, sadness, disappointment, hopelessness). In most conditions, it is assumed that positive activating emotions exert positive effects on achievement whereas negative deactivating emotions exert negative effects, in contrast to positive deactivating and negative activating emotions that are assumed to have ambivalent effects on motivation and cognitive processing (Pekrun, 2006). Nevertheless, there exists little research in which these proposed mediation mechanisms are examined, competitively evaluated, or explored with respect to reverse causality (e.g., cognitive resources as mediators of emotion/achievement relations vs. emotions as mediators of cognitive resources/achievement relations; Pekrun, Goetz, Titz, \& Perry, 2002a; Turner \& Waugh, 2007).

Moderators of Emotion/Achievement Relations. Findings on emotion/achievement relations typically show a wide range of relations for both (test) anxiety and other discrete emotions. Moreover, there exist numerous studies in research on anxiety (Zeidner, 1998, 2007) and other discrete emotions (e.g., Pekrun et al., 2002a; Goetz, Cronjaeger et al., 2010; Goetz, Frenzel, Hall, \& Pekrun, 2008; Goetz et al., 2007) that taken together suggest three primary moderators of emotion/achievement relations:

1. Relations are stronger when emotions and achievement are assessed within a specific domain (e.g., math anxiety and math achievement vs. learning anxiety and GPA).
2. Relations are stronger in the math and science domains as compared to verbal domains.

3. Emotion valence determines relation valence: Pleasant emotions are positively related with achievement and unpleasant emotions are negatively related.

Research on test anxiety and achievement relations suggests additional moderating variables (Zeidner, 1998, 2007), including those that increase these relations (e.g., evaluative settings, negative feedback) and decrease these relations (e.g., structured conditions, social support). Although often cited as a possible moderator, gender has not been found to substantially moderate anxiety/achievement relations (Zeidner, 1998, 2007). Empirical findings concerning gender effects on discrete emotion/achievement relations are presently lacking. With respect to causal ordering, it is important to note that reciprocal relations between emotions and achievement can also be assumed (Pekrun et al., 2002a; for test anxiety, see Zeidner, 1998, 2007). More specifically, achievement can impact emotions (e.g., good grades predict enjoyment) directly or via academic self-concept (e.g., good grades predict perceived competence which predicts enjoyment; Goetz, Frenzel, Hall, \& Pekrun, 2008).

\section{Relevance of Academic Emotions for Academic Achieve-}

ment. Studies indicate that emotion/achievement relations are, on average, weak to moderate in magnitude (cf., academic self-concept/achievement: average $r=.50$ to .70; Marsh \& Craven, 2006). However, even relatively weak effects of emotions on academic achievement may have a strong cumulative impact on students' long-term achievement. The findings outlined above further suggest considerable variability in emotion/achievement relations as a function of emotion type and academic discipline, highlighting the potential for notably stronger relations for specific emotions in specific academic settings (e.g., anxiety in natural science classes). In addition, whereas academic emotions are of relevance to achievement outcomes, their effects also generalize to salient developmental outcomes including health, subjective well-being, career choice, and lifelong learning (Pekrun, 2006). Finally, in light of the dominance of anxiety research, relatively unexplored positive academic emotions have also received recent attention. According to Pekrun, Goetz, Titz, and Perry (2002b), positive emotions "help to envision goals and challenges, open the mind to thoughts and problem-solving, protect health by fostering resiliency, create attachments to significant others, lay the groundwork for individual self-regulation, and guide the behavior of groups, social systems, and nations" (p. 149).

\section{Summary and Recommendations}

Given the importance of academic emotions with respect to achievement outcomes as well as student development, and accounting for the status quo of research in this field, the following research activities are recommended: 
- Research on emotion/achievement relations should focus on discrete emotions, such as enjoyment, hope, pride, gratitude, relaxation, contentment, relief, anger, frustration, anxiety, shame, boredom, sadness, disappointment, and hopelessness in addition to test anxiety.

- Given the domain-specificity of academic emotional experiences and subject domain as a moderator of the strength of emotion/achievement relations, domainspecific investigations are warranted.

- As most research on emotion/achievement relations has focused on testing situations (i.e., anxiety) and the classroom setting, future studies on homework-related emotions remains relatively unexplored and may yield intriguing findings (cf., Dettmers et al., 2011).

- Empirical research examining the assumed causal relations between emotions and achievement is needed (e.g., longitudinal, experimental, intervention designs).

- The continued development of domain- and age-specific instruments for the assessment of discrete emotions other than (test) anxiety is required to adequately explore emotion/achievement relations (e.g., domain-general and domain-specific measures in the Achievement Emotions Questionnaire; Pekrun, Goetz, Frenzel, Barchfield, \& Perry, 2011).

Concerning implications of research on emotion/ achievement relations for teaching and teacher education programs, possible recommendations include:

- The impact of academic emotions on learning and achievement should be highlighted in teacher education curricula.

- Antecedents of academic emotions should also be addressed in teacher education curricula to facilitate teachers' understanding of how students' emotions are affected by the mediating and moderating variables outlined above.

- Based on knowledge of emotion antecedents, teachers should acknowledge their potential to impact students' emotions and attempt to foster pleasant and reduce negative emotions; for example, by enhancing students' academic self-concept (Goetz et al., 2008), adopting an enthusiastic teaching style (Frenzel, Goetz, Lüdke, Pekrun, \& Sutton, 2009), or fostering students' emotion regulation competencies (e.g., for coping with test anxiety, see Zeidner, 1998, 2007; for coping with boredom, see Nett, Goetz, \& Hall, 2011).

- Teachers should also be aware of their own emotional experiences and attempt to optimize their emotions concerning instruction so as to promote students' emotions and achievement (Frenzel et al., 2009; Schutz \& Zembylas, 2009).

It is essential that ongoing empirical research on students' emotions be consistently incorporated into teacher education programs and informed by educational practice.
In this manner, researchers and educators alike will be better able to identify and develop instructional strategies and intervention programs that optimize student's academic emotional experiences and thereby facilitate not only learning and academic achievement, but also critical developmental outcomes including health and psychological well-being.

\section{References}

Dettmers, S., Trautwein, U., Lüdtke, Goetz, T., Frenzel, A. C., \& Pekrun, R. (2011). Students' emotions during homework in mathematics: Testing a theoretical model of antecedents and achievement outcomes. Contemporary Educational Psychology, 36(1), 25-35.

Efklides, A., \& Volet, S. (2005). Feelings and emotions in the learning process [Special issue], Learning and Instruction, 15, 377-380.

Frenzel, A. C., Goetz, T., Lüdtke, O., Pekrun, R., \& Sutton, R. E. (2009). Emotional transmission in the classroom: Exploring the relationship between teacher and student enjoyment. Journal of Educational Psychology, 101(3), 705-716.

Goetz, T., Cronjaeger, H., Frenzel, A. C., Lüdtke, O., \& Hall, N. C. (2010). Academic self-concept and emotion relations: Domain specificity and age effects. Contemporary Educational Psychology, 35, 44-58.

Goetz, T., Frenzel, C. A., Hall, N. C., \& Pekrun, R. (2008). Antecedents of academic emotions: Testing the internal/external frame of reference model for academic enjoyment. Contemporary Educational Psychology, 33, 9-33.

Goetz, T., Frenzel, C. A., Pekrun, R., Hall, N. C., \& Liidtke, O. (2007). Between- and within-domain relations of students' academic emotions. Journal of Educational Psychology, 99(4), 715-733.

Goetz, T., Nett, U., Martiny, S., Hall, N. C., Pekrun, R., Dettmers, S., \& Trautwein, U. (2012). Students' emotions during homework: Structures, self-concept antecedents, and achievement outcomes. Learning and Individual Differences, 22(2), 225-234.

Hembree, R. (1988). Correlates, causes, effects, and treatment of test anxiety. Review of Educational Research, 58, 7-77.

Linnenbrink, E. A. (2006). Emotion research in education: Theoretical and methodological perspectives on the integration of affect, motivation, and cognition [Special issue]. Educational Psychology Review, $18,307-314$.

Linnenbrink-Garcia, E. A., \& Pekrun, R. (2011). Students' emotions and academic engagement [Special issue]. Contemporary Educational Psychology, 36(1), 1-3.

Lipnevich, A. A., \& Roberts, R. D. (2012). Noncognitive skills in education: Emerging research and applications in a variety of international contexts. Learning and Individual Differences, 22(2), 173-177.

Ma, X. (1999). A meta-analysis of the relationship between anxiety toward mathematics and achievement in mathematics. Journal for Research in Mathematics Education, 30(5), 520-540.

Marsh, H., W., \& Craven, R. G. (2006). Reciprocal effects of self-concept and performance from a multidimensional perspective: Beyond seductive pleasure and unidimensional perspectives. Perspectives on Psychological Science, 1(2), 133-163.

Nett, U. E., Goetz, T., \& Hall, N. C. (2011). Coping with boredom in school: An experience sampling perspective. Contemporary Educational Psychology, 36(1), 49-59.

Pekrun, R. (2006). The control-value theory of achievement emotions: Assumptions, corollaries, and implications for educational research and practice. Educational Psychology Review, 18, 315-341.

Pekrun, R., Elliot, A. J., \& Maier, M. A. (2009). Achievement goals and achievement emotions: Testing a model of their joint relations with academic performance. Journal of Educational Psychology, 101, 115-135.

Pekrun, R., Frenzel, A. C., Götz, T. \& Perry, R. P. (2007). The control-value theory of achievement emotions: An integrative approach to emotions in education. In P. A. Schutz \& R. Pekrun (Eds.), Emotion in education, (pp. 13-36). San Diego, CA: Academic Press. 
Pekrun, R., Goetz, T., Daniels, L. M., Stupnisky, R. H., \& Perry, R. P. (2010). Boredom in achievement settings: Exploring control-value antecedents and performance outcomes of a neglected emotion. Journal of Educational Psychology, 102(3), 531-549.

Pekrun, R., Goetz, T., Frenzel, A. C., Barchfeld, P., \& Perry, R. P. (2011). Measuring emotions in students' learning and performance: The achievement emotions questionnaire (AEQ). Contemporary Educational Psychology, 36(1), 36-48.

Pekrun, R., Goetz, T., Titz, W., \& Perry, R. P. (2002a). Academic emotions in students' self-regulated learning and achievement: A program of qualitative and quantitative research. Educational Psychologist, 37(2), 91-105.

Pekrun, R., Goetz, T., Titz, W., \& Perry, R. P. (2002b). Positive emotions in education. In E. Frydenberg (Ed.), Beyond coping: Meeting goals, visions, and challenges (pp. 149-173). Oxford, England: Oxford University Press.

Sarason, S. B., \& Mandler, G. (1952). Some correlates of test anxiety. Journal of Abnormal and Social Psychology, 47(4), 810-817.

Schutz, P. A., \& Lanehart, S. L. (Eds.). (2002). Emotions in education [Special issue]. Educational Psychologist, 37(2).
Schutz, P. A., \& Pekrun, R. (Eds.). (2007). Emotions in education. San Diego, CA: Elsevier.

Schutz, P. A., \& Zembylas, M. (Eds.). (2009). Advances in teacher emotions research: The impact on teachers lives. San Diego, CA: Academic Press.Seipp, B. (1991). Anxiety and academic performance: A meta-analysis of findings. Anxiety Research, 4, 27-41.

Turner, J. E., \& Waugh, R. M. (2007). A dynamical systems perspective regarding students' learning processes: Shame reactions and emergent self-organizations. In P. A. Schutz \& R. Pekrun (Eds.), Emotion in education (pp. 125-145). San Diego, CA: Academic Press.

Weiner, B. (1985). An attributional theory of achievement motivation and emotion. Psychological Review, 92(4), 548-573.

Yerkes, R. M., \& Dodson, J. D. (1908). The relation of strength of stimulus to rapidity of habit-formation. Journal of Comparative and Neurological Psychology, 18, 459-489.

Zeidner, M. (1998). Test anxiety: The state of the art. New York: Plenum Press.

Zeidner, M. (2007). Test anxiety: Conceptions, findings, conclusions. In P. A. Schutz \& R. Pekrun (Eds.), Emotion in education (pp. 165-184). San Diego, CA: Academic Press. 